\title{
UMA ANÁLISE dO PROGRAMA BOLSA FAMÍLIA NA REGIÃO SUL DO BRASIL
}

\author{
Henrique Rogê Batista'
}

\begin{abstract}
Resumo
Em 2004, foi criado o Programa Bolsa Família que incorporou os antigos programas de transferência de renda que vigoravam no Brasil com o objetivo de se estabelecer uma maior organização, além de atender as diferentes famílias na situação de pobreza de acordo com suas diferentes necessidades. Este trabalho tem por objetivo realizar uma análise sobre a atuação do Programa Bolsa-Família na Região Sul do Brasil, tendo em vista as especificidades regionais do país. Como procedimento metodológico, além de um breve levantamento da literatura econômica, foi feito um trabalho estatístico e uma análise qualitativa dos dados do Programa Bolsa Família. Constatou-se na que Região Sul do Brasil o Programa Bolsa Família tem se mostrado potente tanto no alívio mediato da pobreza, quanto no estímulo do produto econômico.
\end{abstract}

Palavras-chave: Programa Bolsa Família, Região Sul e Transferência de Renda.

Classificação JEL: O2, R2, I3.

\section{INTRODUÇÃO}

A pobreza atinge uma considerável parcela da população brasileira distribuída desigualmente no território nacional. O crescimento econômico brasileiro mostrou-se incapaz de erradicar a pobreza, ou reduzi-la a

Mestrando do Instituto de Economia da Universidade Federal de Uberlândia. E-mail: henriqueroge@hotmail.com. Telefone: (34) 3239-4I57. 
patamares bem inferiores. Para Michel (2003) o crescimento econômico só apresenta-se eficiente a este fim em um ambiente econômico onde há igualdade de oportunidades e acesso à educação e à informação; situação socioeconômica que não é observada no Brasil.

Na década de 90 difundiu-se por boa parte da América Latina, inclusive no Brasil, uma nova alternativa de política social centrada no combate à pobreza, derivada dos programas de Renda Mínima da Europa, os denominados Programas de Transferência de Renda Condicionada (PTCR). Dada a importância econômica e social destes programas, a literatura econômica tem elaborado diversos trabalhos buscando entender seus mecanismos de funcionamento, bem como sua eficiência na sociedade.

Para o caso brasileiro, Cotta e Paiva (2010) caracterizam o Programa Bolsa Família (PBF) como divergente dos antigos sistemas de proteção social que visavam combater a pobreza, trata-se, portanto, de uma estrutura de política social "sem precedentes na história da assistência social no Brasil" (COTTA E PAIVA, p.59, 2010). Os autores ainda destacam os efeitos que os programas têm gerado em diversos indicadores sociais, principalmente, nas áreas da saúde, pobreza, desigualdade, segurança alimentar e trabalho.

A análise do caso brasileiro com o PBF admite certas especificidades: primeiro que o Brasil é um país de dimensão continental; segundo, internamente, as grandes regiões brasileiras guardam profundas diferenças sociais e econômicas e; terceiro, a focalização do PBF permite que sua atuação seja demasiadamente concentrada nas regiões onde têm o maior número de pessoas na situação de pobreza. Desta forma, torna-se conveniente a análise regional de tal programa a fim de melhor compreender sua dinâmica.

Neste contexto, este trabalho se propõe a realizar uma análise da incidência do PBF na Região Sul do Brasil. Com esta finalidade, como procedimento metodológico, além de um breve levantamento da literatura econômica sobre os PTRC e o PBF, foi feito um trabalho estatístico em dados coletados no Instituto Brasileiro de Geografia e Estatística (IBGE), no Instituto de Pesquisa Econômica Aplicada (IPEA), no Ministério da Fazenda, no Departamento Intersindical de Estatística e Estudos Socioeconômicos (DIEESE), no Tesouro Nacional, e no Ministério do Desenvolvimento Social e Combate à Fome (MDS).

A fim de cumprir com os objetivos propostos acima, este artigo, além desta introdução apresenta a seguinte organização: na segunda seção realiza- 
se uma breve revisão bibliográfica abrangendo as características dos PTRC; na terceira seção é realizado um ligeira caracterização do PBF apresentando seu desenho institucional; na quarta seção é analisada a incidência do PBF na Região Sul do Brasil, destacando sua dimensão tanto do ponto de vista monetário, quanto no número de famílias atendidas. Por fim, o trabalho é finalizado com as considerações finais, destacando os principais resultados e a relevância do PBF para a Região Sul, bem como da necessidade de reajustes nas políticas sociais vinculadas ao programa visando a ampliação dos seus resultados no longo prazo.

\section{OS PROGRAMAS DE TRANSFERÊNCIA DE RENDA CONDI- CIONADOS}

Pinheiros (1995) interpreta as políticas sociais como parte componente do funcionamento dos sistemas econômicos, desta forma, a fim de entender o mecanismo de funcionamento das políticas sociais, inclusive as de combate à pobreza, é necessário compreender a dinâmica capitalista do sistema econômico do período analisado.

Os PTRC são descendentes, segundo Fonseca (2006) apud Silva (2009), dos programas europeus de Renda Mínima dos anos de 1930 que visavam garantir proteção social às famílias pobres e, consequentemente, atuavam como um importante instrumento de combate à pobreza e de garantia de uma vida digna.

Os resultados dos PTRC quanto às suas principais metas voltadas à redução da pobreza e extrema pobreza se mostraram eficazes segundo uma parcela considerável da literatura especializada ${ }^{2}$. Todavia, a eficiência dos PTCR em economias periféricas é demasiadamente questionável, apesar de estes programas terem sido disseminados rapidamente em países na América Latina, Caribe, África e Ásia, principalmente, em virtude das características de seu desenho institucional, quais sejam: a facilidade de aplicação e de atuação em paralelo com outros programas de proteção social.

Na América Latina, os PTRC surgiram nos anos de 1990, onde a maioria dos países apresentava, de acordo com Silva (2009), sistemas corporativos de proteção social caracterizados por serem segmentados, heterogêneos,

$2 \operatorname{Ver}($ Soares, 2007), (Hoffmann, 2007) e (Rocha, 2005). 
de baixa cobertura populacional e reduzida garantia de direitos sociais. Os PTRC são distintos das anteriores políticas sociais que vigoraram na América Latina em virtude da presença das condicionalidades no seu desenho institucional. Os PTRC buscam influenciar o comportamento dos adultos da família para aquilo considerado "viável" como, por exemplo, investimentos na saúde e educação dos membros mais jovens da família. O prêmio financeiro pago às famílias é o que garante a possibilidade de indução do comportamento dos membros adultos sob risco de não mais receber o benefício. Da mesma forma, Cotta (2009) apresenta, complementarmente ao já mencionado, duas novas características dos PTRC, quais sejam: o foco na demanda e os custos de transações menores.

Ao analisar o caso da América Latina, os PTRC guardam diferentes especificidades quanto a sua estrutura, configuração, origem e resultados. Por outro lado, é possível traçar os denominadores em comum de tais programas de transferência de renda condicionada:

São programas do tipo auxílios monetários e, pela espécie, definem-se como transferências monetárias assistenciais, ou de base não-contributiva; utilizam as transferências como incentivos à demanda, com vistas a modificar os comportamentos individuais; o benefício é entregue preferencialmente à mulher e destina-se a família como um todo, e não a cada um de seus membros individualmente; Sua clientela-alvo é constituída por famílias muito pobres, preferencialmente as famílias com filhos em idade escolar; e (...)operam com condicionalidades, isto é, a entrega do benefício tem como contrapartida o cumprimento, por parte dos membros da família, de requisitos nas áreas da educação (matrícula e frequência mínima às aulas) e saúde (frequência aos serviços de saúde) e, em alguns casos, capacitação e procura de trabalho. (DRAIBE, 2009, p.5-6).

Diversos trabalhos têm mostrado como os PTRC, especialmente para o caso brasileiro do PBF, vêm contribuindo para a redução da desigualdade de renda e da pobreza, além de promover a inclusão social com garantias básicas de vida e a elevação do capital humano.

Os PTRC incidem sobre os índices de pobreza e extrema pobreza em duas vias: a de mais curto prazo, que se configura como o alívio imediato da pobreza via transferência monetária; e o de mais longo prazo, que se 
dá a partir da promoção do capital humano dos membros mais jovens das famílias beneficiadas. Enquanto atua na redução da pobreza, estes programas de transferência agem também, principalmente, sobre a desigualdade de renda e ao estímulo econômico na região.

A particularidade dos PTRC, quando comparado com outros programas de proteção social, encontra-se em atuar simultaneamente sobre as consequências e causas da pobreza, o programa procura agir no sentido de aliviar a pobreza imediata e na redução da pobreza futura. Partindo desta particularidade, Cotta (2009, p.98) divide os objetivos dos PTRC em: imediatos, mediatos e finais. Desta forma, os objetivos imediatos estão voltados à ampliação e disseminação às famílias pobres ao acesso aos serviços de educação e saúde; os objetivos mediatos são o desenvolvimento da escolaridade, estado de saúde e nutricional das famílias pobres e, consequentemente, à melhoria dos indicadores de saúde e educação; e os objetivos finais se traduzem na ruptura do que a autora definiu como "ciclo intergeneracional de pobreza" que se dá via inserção positiva dos jovens no mercado de trabalho.

Medeiros (2003) define os eixos de políticas públicas para o combate da pobreza no curto prazo como políticas compensatórias focalizadas nos grupos excluídos do pacto dominante que ainda são eficientes, segundo a literatura, em reduzir o grau de concentração de renda, para o caso brasileiro. Os impactos dos PTRC no curto prazo, segundo Lopes (1995) apud Cohn (1995), são aqueles de caráter mais emergencial que consistem na focalização de famílias que se enquadram na situação de pobreza, visando resultados imediatos quanto ao alívio à pobreza.

No longo prazo, os PTRC agem sobre as razões estruturais que levam à pobreza ou a sua reprodução. Lopes (1995) apud Cohn (1995, p. 7) apresentam os efeitos de longo prazo como mais universais, permanentes e os caracterizado como "um novo modelo de desenvolvimento sustentado, que priorize o crescimento econômico com equidade social e no qual as políticas econômicas assumem também a dimensão de políticas sociais".

Apesar de duas vias distintas de ação sobre a pobreza, os mecanismos de curto e longo prazo dos PTRC encontram-se articulados entre si, uma vez que a garantia da continuidade da transferência de renda exige que as condicionalidades sejam respeitadas implicando, consequentemente, no alívio mediato e na criação de mecanismos que impeçam a perpetuação da pobreza familiar. Cohn (1995) defende a articulação entre as ações pú- 
blicas de combate à pobreza de curto e longo prazo, quando a finalidade é o alívio imediato e a superação da pobreza. Da mesma forma, Medeiros (2003) chama a atenção para a ineficiência no combate à pobreza quando adotado apenas a estratégia de transferência monetária, que segundo o autor deve ser acompanhada por outras ações do governo que se traduzem nos mecanismos de longo prazo.

\subsection{O Programa Bolsa Família}

A literatura aponta para a existência dos PTRC no Brasil com atuação municipal antes da consolidação dos programas nacionais. Porém, somente na década que 90 que os PTRC iriam adquirir maior importância com cobertura mais ampla de famílias. Neste contexto, em 2000 é implantado o Auxílio Gás que visava subsidiar às famílias pobres, com pagamento bimestral, a compra de botijão de gás de cozinha; em 2001 o Bolsa Escola surge com o objetivo de incentivar a permanência das crianças das famílias pobres nas escolas; também criado em 2001 o Bolsa Alimentação visava melhorar a situação de saúde e nutrição de gestantes, nutrizes e crianças com seis meses a seis anos e onze meses de idade, respeitadas as condicionalidades; e em 2003 o Cartão Alimentação visava assegurar a alimentação das famílias pobres.

Durante o governo Lula, com a criação do Ministério do Desenvolvimento Social e Combate à Fome em 2004, o Programa Bolsa Família incorporou os antigos programas de transferência de renda por meio da transferência dos beneficiários, com o objetivo de se estabelecer uma maior organização, além de atender as diferentes famílias de acordo com suas diferentes necessidades. A transferência de renda, que tinha como foco as pessoas de mais baixa renda, foi unificada e seus parâmetros determinados por tal programa, com o diferencial da ampliação do número de pessoas atendidas, bem como o aumento no valor transferido. Segundo Santana (2007, p.4), o Programa Bolsa Família, com o objetivo de combater a fome e a miséria e de criar mecanismos para que futuramente as famílias mais pobres do país não venha necessitar do programa, vai redefinir os parâmetros de renda para delimitação das famílias beneficiárias, bem como as regras para a determinação do valor de transferência. O desenho do programa é de tal modo que privilegia famílias pobres com crianças, mas sem deixar de atender aquelas que não possuem crianças. 
O PBF prioriza a família como unidade de intervenção social, vinculado ao Fome Zero ${ }^{3}$, o programa tem como objetivo assegurar o direito humano à alimentação, promover a segurança alimentar e nutricional e promover a conquista da cidadania. O PBF é estruturado basicamente em três eixos: a transferência de renda, as condicionalidades e os programas complementares.

Os benefícios do programa são transferidos mensalmente e se dividem entre fixo e variável. A seleção das famílias beneficiadas se dá unicamente pelo critério da renda mensal per capita. Estas transferências permitem o alívio mediato na composição da renda familiar, cujo valor visa não desmotivar os membros adultos das famílias ao trabalho. A composição dos benefícios do PBF está exposta no Quadro 1.

Quadro 1 - Valor dos benefícios do Programa Bolsa Família*

\begin{tabular}{|c|c|c|c|c|}
\hline Situação da Família & $\begin{array}{c}\text { Renda Familiar } \\
\text { Mensal (per capita) }\end{array}$ & $\begin{array}{c}\text { Benefício } \\
\text { Mensal do PBF }\end{array}$ & $\begin{array}{c}\text { Valor } \\
\text { Mínimo }\end{array}$ & $\begin{array}{c}\text { Valor } \\
\text { Máximo }\end{array}$ \\
\hline Extremamente Pobre & Até $\mathrm{R} \$ 70,00$ & & & \\
\hline Sem filhos & & $\begin{array}{l}\text { Piso Básico: } \\
\text { R } \$ 70,00\end{array}$ & $\mathrm{R} \$ 70,00$ & $\mathrm{R} \$ 70,00$ \\
\hline $\begin{array}{l}\text { Com Filhos } \\
\text { (até } 5 \text { filhos**) }_{\text {Com Jovens }} \\
(\text { até } 2 \text { jovens } \\
\text { (a**) }\end{array}$ & & $\begin{array}{c}\text { Piso Básico: } \\
\text { R } \$ 70,00+ \\
\text { Variável: } \mathrm{R} \$ 32,00 \\
\text { + BVJ: } \mathrm{R} \$ 38,00\end{array}$ & $\mathrm{R} \$ 70,00$ & $\mathrm{R} \$ 306,00$ \\
\hline Pobres & $\begin{array}{c}\text { Superior a } \mathrm{R} \$ 70,00 \mathrm{e} \\
\text { inferior a } \mathrm{R} \$ 140,00\end{array}$ & & & \\
\hline $\begin{array}{l}\text { Com Filhos } \\
\text { (até } 5 \text { filhos }^{* *} \text { ) } \\
\text { Com Jovens } \\
\text { (até } 2 \text { jovens***) }\end{array}$ & & $\begin{array}{l}\text { Variável: } \mathrm{R} \$ 32,00 \\
\text { + BVJ: } \mathrm{R} \$ 38,00\end{array}$ & $\mathrm{R} \$ 32,00$ & $\mathrm{R} \$ 236,00$ \\
\hline
\end{tabular}

Fonte: MDS (2012). *O valor dos benefícios do PBF ainda está sujeitos ao Benefício Variável de Caráter Extraordinário (BVCE) cujo valor é calculado caso a caso.**Filhos com idade entre zero e 15 anos. ***Jovens com idade entre 16 e 17 anos que faz parte do Benefício Variável Vinculado ao Adolecente (BVJ).(Elaboração Própria).

Para ter direito a receber e manter continuidade das transferências do PBF as famílias beneficiadas encontram-se sujeitas às condicionalidades,

\footnotetext{
O Fome Zero é um estratégia do "governo federal para assegurar o direito humano à alimentação adequada às pessoas com dificuldades de acesso aos alimentos (...) se insere na promoção da segurança alimentar e nutricional buscando a inclusão social e a conquista da cidadania da população mais vulnerável à fome" MDS (20 l 2).
} 
que são compromissos assumidos por elas nas áreas da saúde, educação e assistência social. As condicionalidades permitem ampliar o acesso destas famílias aos seus direitos sociais básicos e, como apresentado anteriormente, age, negativamente, sobre a continuidade da pobreza no longo prazo, uma vez agindo como mecanismo para romper com a continuidade da pobreza.

$\mathrm{Na}$ área da saúde as famílias devem acompanhar o cartão de vacina e o desenvolvimento das crianças com menos de 7 anos, quando lactantes ou gestantes a realização do pré-natal e o acompanhamento da saúde do bebê, também são exigidos. Na área da educação, crianças e adolescentes entre6 e 15 anos além de matriculados deve manter frequência escolar igual ou superior a $85 \%$ da carga horária, a frequência escolar reduz para $75 \%$ aos estudantes entre 16 e 17 anos. Na área da assistência social, crianças e adolescentes, com idade de até 15 anos, em risco de ingressarem no trabalho infantil ou que foram retiradas do trabalho infantil devem frequentar os Serviços de Convivência e Fortalecimento de Vínculos e do Programa de Erradicação do Trabalho Infantil e, consequentemente, atingir $85 \%$ da carga horária escolar.

Os eixos da transferência de renda e das condicionalidades encontramse vinculados, uma vez que a garantia das transferências mensais dependem do cumprimento das condicionalidades do programa. Ressalta-se, entretanto, que o não cumprimento de uma dada condicionalidade não implica, imediatamente, no cancelamento do benefício, fica a cargo do poder público fazer o acompanhamento e identificar as causas do não cumprimento e, a partir dai, são implementadas as ações de acompanhamento. Somente quando esgotado as tentativas de reverter o descumprimento das condicionalidades que o benefício pode ser bloqueado, suspenso ou cancelado.

Por fim, o terceiro eixo compreende os programas complementares onde são oferecidos às famílias beneficiadas condições para superar a condição de pobreza, ou seja, assim como as condicionalidades, também age no sentido de romper com a perpetuação da pobreza na família. De acordo com o MDS são programas articulados em três etapas: diagnóstico que permite identificar a vulnerabilidade no público alvo; o planejamento das ações a serem tomadas, bem como a execução, levando em conta as especificidades locais; e o acompanhamento dos resultados visando a melhoria e fortalecimento dos projetos. Estes programas complementares além de voltados à 
escolarização também visa a "qualificação e inserção profissional, formação de micrompreendimentos, concessão de microcrédito, estratégia de apoio à aquisição, (...) produção e acesso à cultura e emissão de documentos de identificação civil” (MDS, 2012).

\section{O PROGRAMA BOLSA FAMÍLIA NA REGIÃO SUL}

A estrutura econômica brasileira tem como uma de suas características a elevada disparidade econômica e social entre as cinco grandes regiões geográficas que formam o país. Tal desigualdade é fruto do processo de formação histórica brasileira o que, consequentemente, resultou em regiões com diferentes participações no produto econômico, no nível de industrialização, na renda, na concentração da pobreza, dentre outros elementos. Estas disparidades regionais influenciam na distribuição espacial dos recursos do PBF, bem como na quantidade de famílias beneficiadas, tendo em vista o caráter focalizador do programa. Desta forma, uma análise regional do PBF permite obter detalhes da incidência do programa que não seriam possíveis em uma análise nacional. Tendo isto em vista, esta seção se divide em duas partes, na primeira é analisada a distribuição regional do PBF entre as grandes regiões brasileiras, e na segunda são apresentados elementos que apontam a relevância do programa na Região Sul do Brasil.

\subsection{A Heterogeneidade do Programa Bolsa Família entre as Grandes Regiões Brasileiras}

No Gráfico 1, analisando a distribuição espacial média dos recursos do PBF entre as Grandes Regiões do Brasil, entre os anos de 2004 e 2010, constata-se que as Regiões Nordeste e Sudeste, as que apresentam maior volume absoluto de pobreza, foram os principais destinos de tais recursos com $53 \%$ e $24 \%$, respectivamente. Por outro lado, as Regiões Centro-Oeste e Sul foram as que apresentaram menor participação nos recursos com 8\% e $5 \%$, respectivamente.

Dois fatores, principalmente, são os responsáveis por tal heterogeneidade na distribuição espacial dos recursos do PBF. O primeiro deles éa 
estimativa de famílias pobres ${ }^{4}$, elaborado pelo MDS, que aponta as localidades para onde são direcionados maiores esforços no combate à pobreza, uma vez o programa estar focalizado nas famílias situadas abaixo da linha da pobreza. Em 2010, as Regiões Centro-Oeste, Sul e Norte foram as que apresentaram menor percentual de famílias estimadas pobres no Brasil com $6,07 \%, 9,71 \%$ e $9,87 \%$, respectivamente; por outro lado as Regiões Nordeste e Sudeste concentraram quase três-quartos das famílias estimadas pobres no Brasil, com 46,93\% e 27,41\%, respectivamente. O segundo fator responsável pela desigualdade na distribuição dos recursos do PBF é cobertura $^{5}$ do programa, ou seja, o percentual de famílias estimadas pobres pelo MDS que recebem o benefício do PBF. Ainda de acordo com o MDS, em 2010, a região Nordesteé a que possui os maiores níveis de cobertura, contrastando com a Região Sul que possui os menores níveis de cobertura do Brasil, entretanto, as três Unidades Federativas que compões a região apresentam grau de cobertura superior a $83 \%$.

Gráfico 1 - Grandes Regiões: média entre os anos de 2004-2011 do total de recursos transferidos pelo PBF

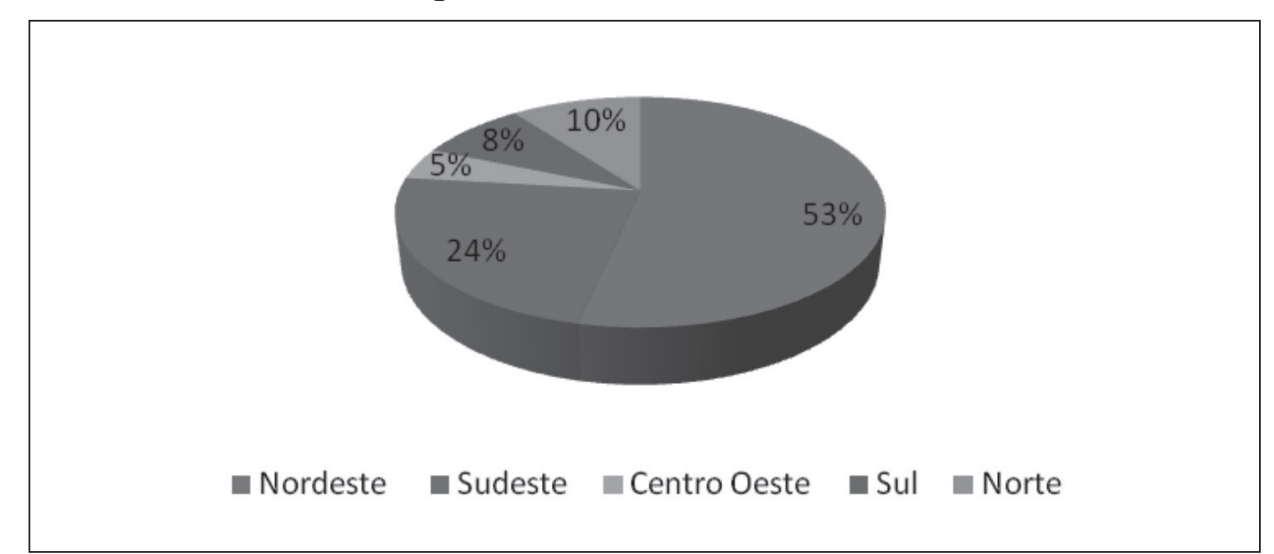

Fonte: MDS, SAGI - Matriz de Informações Sociais, 2010. (Elaboração Própria)

4 A estimativa de famílias pobres, do MDS, com base no perfil de inclusão no Programa Bolsa Família leva em consideração a renda familiar per capita de até R\$140,00. Os dados considerados são referentes à PNAD de 2006.

Expressa a cobertura do Programa Bolsa Família em relação à estimativa de famílias pobres que se enquadram no perfil de inclusão do Programa. Até março de 2009, o indicador foi calculado utilizando como denominador, a variável "Estimativa de Famílias Pobres - Meta de atendimento Bolsa Família (Pnad 2004)" (famílias com renda familiar per capita de até $\mathrm{R} \$ 100,00$ ) e, a partir de abril de 2009, utilizando a variável "Estimativa de Famílias Pobres - Perfil Bolsa Família (Pnad 2006)" (famílias com renda familiar per capita de até R\$140,00). 
No Brasil, em 2004 quando implementado o PBF, mais de 6,5 milhões de famílias recebiam as transferências do programa; em 2010 o número de famílias atendidas expandiu 94,43\%, com mais de 12,7 milhões de famílias sendo beneficiadas.

A distribuição espacial das famílias beneficiadas também é desigual entre as Grandes Regiões do Brasil e as causas são as mesmas que explicam heterogênea distribuição espacial dos recursos do programa. OGráfico 2ilustra a distribuição espacial média das famílias atendidas pelo PBF nas Grandes Regiões do Brasil, entre os anos de 2004 e 2010, e como pode ser observado, as Regiões Nordeste e Sudeste foram as que apresentaram maior média de famílias beneficiadas: $50 \%$ e 26\% respectivamente; as Regiões Sul e Centro -Oeste com 5\% e 9\%, respectivamente, apresentam as menores proporções.

Gráfico 2 - Grandes Regiões: média entre os anos de 2004-2010 do total de famílias atendidas pelo PBF

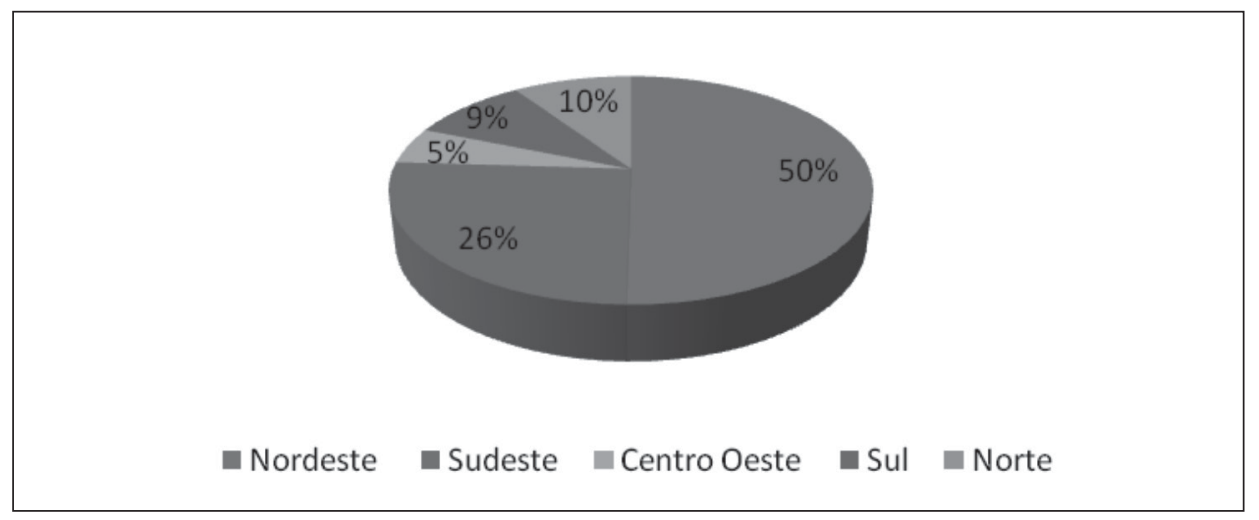

Fonte: MDS, SAGI - Matriz de Informações Sociais, 2010. (Elaboração Própria)

\subsection{A Dimensão do Programa Bolsa Família na Região Sul}

Geograficamente, segundo o IBGE, a Região Sul do Brasil apresenta extensão territorial de pouco mais de 563,8 milhões de $\mathrm{Km}^{2}$, em 2010 com 27.022.098 habitantes a região respondia por $14,55 \%$ da população brasileira. Em 2009, com 11,57\% da população na situação de pobreza, a Região Sul é a que apresentava a menor proporção de pessoas com renda domiciliar 
per capita inferior à linha da pobreza ${ }^{6}$. Como pode ser observado no Gráfico 3, todos os Estados que compõe a Região Sul apresentam um percentual de pobreza inferior à média brasileira, que em 2009 foi de 21,42\%. Além disto, verifica-se que esta região acompanhou a tendência nacional de redução constante do número de pessoas na situação de pobreza desde 2004, com exceção de Santa Catarina em 2008 que apresentou elevação de 0,25 p.p.. Dos três Estados que compõe a região, Santa Catarina é a que apresenta menor percentual de pobreza, 6,36\% em 2009, o equivalente à metade do percentual observado no Paraná e no Rio Grande do Sul com 12,37\% e $13,71 \%$, respectivamente, também para o ano de 2009.

Gráfico 3 - Brasil, Região Sul e Unidades Federação da Região Sul: Percentual de pobreza (em \%)

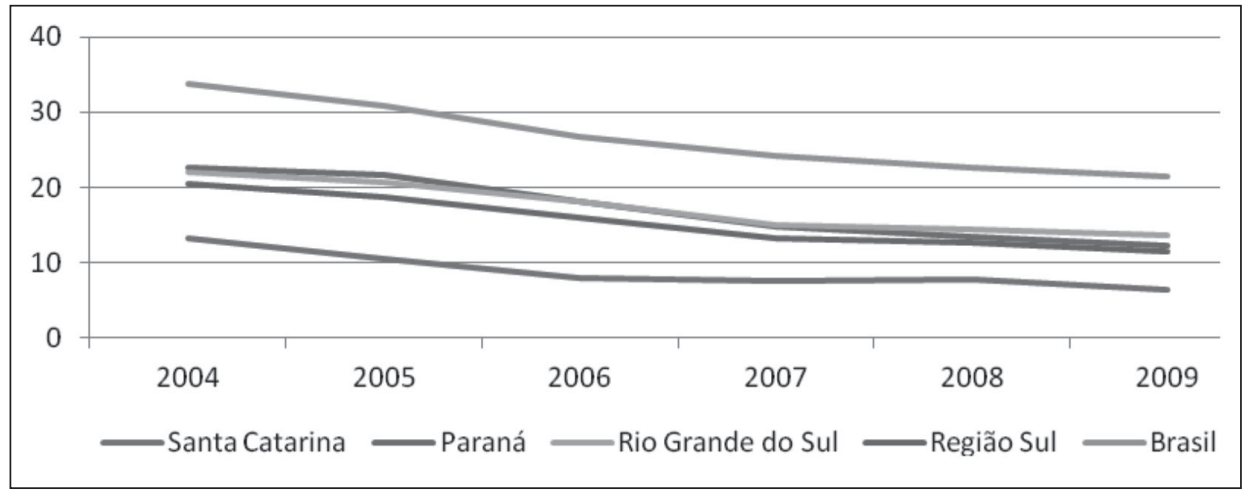

Fonte: IPEADATA - Social 2010. (Elaboração Própria).

Como mencionado anteriormente, a proporção de famílias abaixo da linha de pobreza, dado o perfil focalizador do PBF, interfere diretamente na distribuição espacial dos recursos do programa. O Gráfico 4 apresenta esta evolução, os valores apresentados foram deflacionados com base no Índice Nacional de Preços ao Consumidor (INPC) com base no ano de 2010. Nas três Unidades Federativas que compõe a região o aumento nas

\footnotetext{
6 A linha de pobreza aqui considerada é a disponibilizada pelo IPEA que consiste no "dobro da linha de extrema pobreza, uma estimativa do valor de uma cesta de alimentos com o mínimo de calorias necessárias para suprir adequadamente uma pessoa, com base em recomendações da FAO e da OMS. São estimados diferentes valores para 24 regiões do país. Série calculada a partir das respostas à Pesquisa Nacional por Amostra de Domicílios (Pnad/IBGE)".
} 
transferências foi constante, entre os anos de 2004 e 2010, a elevação na região do valor real transferido foi de $142,93 \%$ totalizando, em 2010, mais de 1,096 bilhões de reais.

O aumento no valor repassado às famílias pode ser interpretado como demandas por melhorias nas condições sociais dos grupos vulneráveis que fazem parte do público alvo do programa, além de, como consta no desenho institucional, permitir a garantia do bem-estar vinculado à cidadania.

O total transferido à Santa Catarina ampliou em mais de 105\% nos sete anos analisados, recebendo mais de 145 milhões reais em 2010; a elevação do total transferido foi superior a 154\% no Paraná que, em 2010, recebeu mais de 465 milhões do PBF; por fim, no Rio Grande do Sul as transferências em 2010,484 milhões de reais, foram quase 146\% superiores às de 2004.

A distribuição dos recursos foi bastante desigual, o total das transferências para Santa Catarina são inferiores à 50\% do que é transferido para o Paraná ou para Rio Grande do Sul, isto se deve, sobretudo, ao próprio desenho institucional do PBF que focaliza e canaliza os recursos às famílias pobres que compõe o foco e alvo do programa. Por apresentar um menor percentual de pobreza, como apontado anteriormente, o total de famílias atendidas também é menor, o que reflete no menor montante anual transferido à Santa Catarina, relativo às outras duas Unidades Federativas.

Gráfico 4 - Unidades da Federação da Região Sul: Valor real das transferências do PBF (em milhões de R\$, reais de 2010), 2004-2010

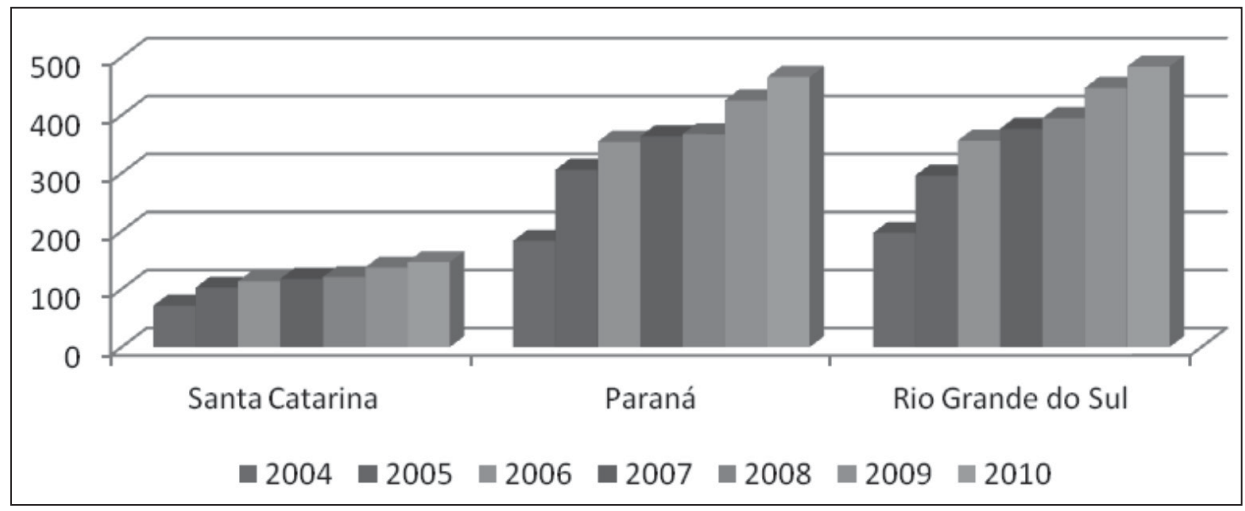

Fonte: MDS, SAGI - Matriz de Informações Sociais, 2010. Valores reais de 2010. (Elaboração Própria). 
A distribuição espacial das famílias beneficiadas pelo PBF na Região Sul é apresentado no Gráfico5. A focalização do programa nas famílias pobres tomando como critério único de seleção a rendaper capita familiar explica a diferença na quantidade de famílias beneficiadas em cada Unidade Federativa. Diferente do aumento linear no valor real transferido pelo programa, o total de famílias beneficiadas oscilou no período considerado, apresentando pico, nas três Unidades da Federação, no ano de 2009.

No ano da criação do PBF mais de 700 mil famílias da Região Sul eram atendidas pelo programa, em 2010 com elevação de 51,87\%, mais de 1,064 milhões de famílias recebiam o benefício do programa. O Rio Grande do Sul foi a unidade federativa que apresentou maior elevação, o equivalente a 56,11\%; Paraná e Santa Catarina aumentaram o número de famílias beneficiadas em $51,13 \%$ e $41,93 \%$, respectivamente.A quantidade de famílias beneficiadas aponta a importância do PBF na distribuição da renda a favor, principalmente, das famílias situadas na extrema pobreza.

Gráfico 5 - Unidades da Federação da Região Sul: Total de famílias atendidas pelo PBF (em milhares), 2004-2010

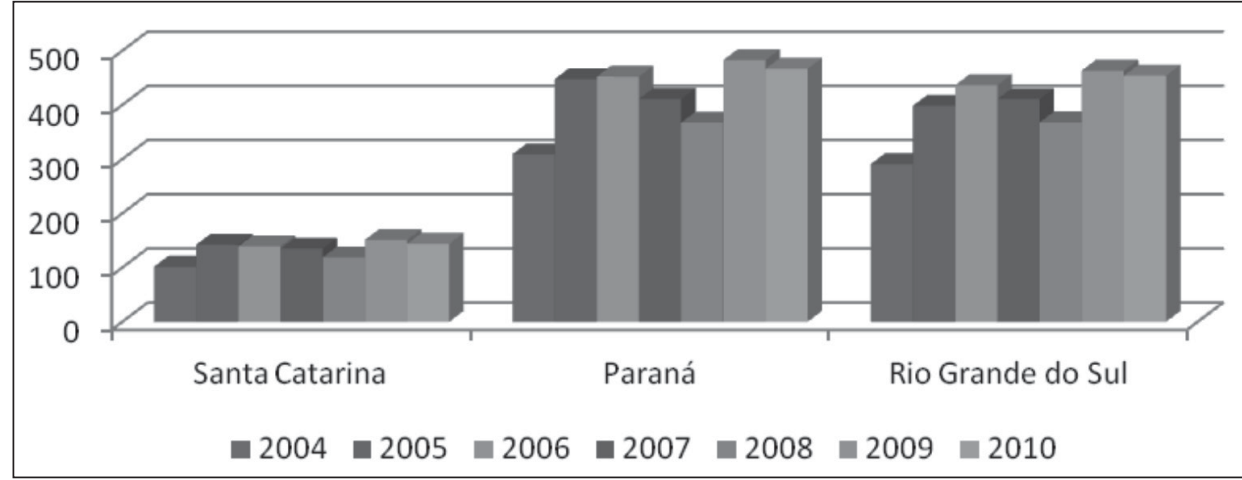

Fonte: MDS, SAGI - Matriz de Informações Sociais, 2010. (Elaboração Própria).

Todavia, mesmo concentrando uma baixa proporção dos recursos e do total de famílias atendidas relativo às demais regiões, o PBF também tem se mostrado relevante para a Região Sul do Brasil. O percentual das famílias atendidas pelo programa sobre o total de famílias estimadas pobres, avaliado pelo MDS, permite visualizar tal importância na distribuição da renda 
a favor das camadas mais pobres, aTabela1 apresenta estes dados levando em consideração as PNADs de 2004 e de 2006.

Em 2004 quando os antigos programas de transferência de renda condicionada do governo Fernando Henrique Cardoso foram, gradualmente, unificados no atual PBF o percentual de famílias pobres atendidas por tal programa na Região Sul, 75,58\%, admitia proporções bem superiores à média nacional, com menos de $60 \%$ das famílias estimadas pobres recebendo o benefício. A situação se inverte dois anos depois, em 2006 o percentual nacional de famílias estimadas pobres atendidas pelo PBF supera o percentual da Região Sul, isto se deve, sobretudo, à maior cobertura que foram alcançadas nas Regiões Nordeste e Sudeste do Brasil. Mesmo inferior à média nacional, a Região Sul ainda apresenta considerável amplitude sendo a terceira grande região brasileira no percentual de famílias pobres atendidas pelo PBF.

Tabela 1 - Brasil e Região Sul: famílias atendidas pelo PBF, 2004 e 2006.

\begin{tabular}{l|c|c|c|c}
\hline \multirow{2}{*}{} & \multicolumn{2}{|c|}{2004} & \multicolumn{2}{c}{2006} \\
\cline { 2 - 5 } $\begin{array}{l}\text { Estimativa de famílias Pobres } \\
\text { PNAD }\end{array}$ & Região Sul & Brasil & Região Sul & Brasil \\
\hline Famílias beneficiadas pelo PBF & 700.661 & 6.571 .839 & 1.027 .439 & 10.965 .810 \\
\hline $\begin{array}{l}\text { \% das famílias estimadas } \\
\text { pobres que recebem o PBF }\end{array}$ & 75,58 & 59,19 & 81,37 & 84,38 \\
\hline
\end{tabular}

Fonte: MDS, SAGI - Matriz de Informações Sociais, 2010. (Elaboração Própria)

A ampliação da parcela das famílias estimadas pobres ${ }^{7}$ atendidas pelo PBF demandou a ampliação do montante transferido mensalmente pelo programa, como apresentado no Gráfico 4, constata-se um crescimento real anual contínuo para as três Unidades Federativas que compõe a região.

No que se refere ao valor médio do benefício do PBF, a Tabela 2 apresenta sua evolução, os valores apresentados também foram deflacionados com base no INPC, com base no ano de 2010 .

\footnotetext{
Apesar da pobreza na Região Sul e no Brasil ter reduzido entre 2004 e 20 I 0, como apresentado no Gráfico3, os dados referentes à Tabela I apontam para a sua elevação, esta divergência se deve a dois motivos: o primeiro se deve à linha de pobreza da PNAD de 2006 ser superior a de 2004; o segundo motivo é que os dados se referem à estimativa de famílias pobres que compõe a meta de atendimento do PBF, e não a quantidade absoluta de pobres.
} 
Para o período analisado, observa-se um crescimento real anual contínuo desde a criação do programa até o ano de 2008, apesar da redução do valor real em 2009, o ano de 2010 registra o maior valor médio mensal transferido pelo PBF ao longo do período analisado. Ressalta-se, ainda, o considerável aumento nos valores reais médio das tranferências, cuja elevação foi superior à 90\% nas três Unidades Federativas que compõe a Região, com deste para o Paraná cuja variação percentual foi superior à $125 \%$.

Tabela 2 - Unidades da Federação da Região Sul: Valor médio mensal do PBF (em reais de 2010), 2004-2010

\begin{tabular}{l|c|c|c|c|c|c|c|c}
\hline & $\mathbf{2 0 0 4}$ & $\mathbf{2 0 0 5}$ & $\mathbf{2 0 0 6}$ & $\mathbf{2 0 0 7}$ & $\mathbf{2 0 0 8}$ & $\mathbf{2 0 0 9}$ & $\mathbf{2 0 1 0}$ & $\begin{array}{c}\text { Variação } \\
\text { Percentual } \\
\text { (2004-2010) }\end{array}$ \\
\hline Santa Catarina & 43,90 & 47,60 & 55,59 & 61,91 & 76,83 & 72,10 & 85,02 & 93,67 \\
\hline Paraná & 36,98 & 45,06 & 53,33 & 62,63 & 75,50 & 69,96 & 83,23 & 125,03 \\
\hline Rio Grande do Sul & 42,19 & 48,99 & 55,57 & 64,99 & 81,11 & 76,58 & 88,92 & 110,73 \\
\hline
\end{tabular}

Fonte: MDS, SAGI - Matriz de Informações Sociais, 2010. Em R\$, valores reais de 2009. (Elaboração Própria).

A Tabela 3 relaciona o valor médio mensal dos benefícios do PBF com a renda média mensal de cada Unidade Federativa. Desta forma, apesar de críticas sobre o reduzido valor repassado às famílias, as transferências do programa equivalem, para o período analisado,a $8,35 \%$ da renda de um indivíduo adulto da região.

Em Santa Catarina a relação é decrescente até 2007, período no qual a variação anual da renda foi superior ao aumento do valor médio repassado pelo PBF; em 2008 esta tendência se reverte fazendo tal relação apresentar o maior valor do período analisado; em 2009 o aumento da renda associado à redução no valor médio do benefício resultaram, novamente, na redução de tal relação. Paraná e Rio Grande do Sul apresentaram comportamento semelhante: elevação na relação entre 2004 e 2008, quando o aumento no valor médio do benefício foi superior ao aumento da renda em cada Unidade Federativa; e decrescendo em 2009 devido a redução no valor médio do benefício e o incremento positivo na renda média.

A variação percentual na relação da renda média com o valor médio das transferências do PBF na Região Sul foi superior a 10\%, porém quando analisado separadamente cada Unidade Federativa observa-se certa hetero- 
geneidade em tal relação. Santa Catarina foi a única a apresentar redução na variação percentual, além de possuir a menor relação média; este comportamento se deveu a um conjunto de fatores: a maior renda média na região, a maior variação positiva na renda média no período analisado e a menor variação positiva das transferências do PBF. Por outro lado, Paraná apresentou a maior variação percentual na relação, uma vez o aumento do valor médio das transferências terem mais que o dobro do aumento da renda média.

Tabela 3 - Unidades da Federação da Região Sul: Relação percentual entre o valor médio mensal das transferências do PBF com a renda média mensal de cada Estado, 2004-2009

\begin{tabular}{l|c|c|c|c|c|c|c}
\hline & $\mathbf{2 0 0 4}$ & $\mathbf{2 0 0 5}$ & $\mathbf{2 0 0 6}$ & $\mathbf{2 0 0 7}$ & $\mathbf{2 0 0 8}$ & $\mathbf{2 0 0 9}$ & $\begin{array}{c}\text { Variação } \\
\text { Percentual } \\
\text { (2004-2009) }\end{array}$ \\
\hline Santa Catarina & 8,04 & 7,49 & 7,62 & 7,99 & 8,99 & 7,43 & $-7,54$ \\
\hline Paraná & 6,97 & 7,95 & 8,60 & 8,64 & 9,81 & 8,54 & 22,57 \\
\hline Rio Grande do Sul & 7,56 & 8,23 & 8,36 & 9,26 & 10,04 & 8,80 & 16,29 \\
\hline
\end{tabular}

Fonte: MDS, SAGI - Matriz de Informações Sociais, 2010 e IPEADATA - Social 2010. (Elaboração Própria).

A partir do valor médio mensal dos benefícios do PBF é possível, também, estabelecer um paralelo com o custo da cesta básica em cada Unidade Federativa. Os valores da cesta básica ${ }^{8}$, calculados pelo Departamento Intersindical de Estatística e Estudos Socioeconômicos (DIEESE),correspondem ao mínimo necessário para um indivíduo adulto repor suas energias. Tomando como base os anos de 2004 à 2008, o preço mensal da cesta de alimentos, na Região Sul, avaliados pelo DIEESE foi de $\mathrm{R} \$ 196,01$ por indivíduo.

A partir dos dados do DIEESE e do MDS estimou-se o valor monetário $^{9}$ referente à cesta básica que corresponde às necessidades alimentares mínimas de uma família. O valor médio, entre 2004 e 2008, na Região Sul foi de $\mathrm{R} \$ 452,60$; em Santa Catarina o valor médio foi de R \$442,93; Paraná com média de $\mathrm{R} \$ 443,56$ e Rio Grande do Sul com média de $\mathrm{R} \$ 471,32$.

\footnotetext{
A cesta básica calculada pelo Dieese é composta por: carne, leite, feijão, arroz, farinha, batata, tomate, pão, café, banana, açúcar, óleo e manteiga.

9 O valor monetário da cesta básica foi calculado com base na metodologia apresentada por PEQUENO (2008), adaptando o número de indivíduos que compõe uma família, onde foi considerado o tamanho médio da família de cada Unidade Federativa da Região Sul disponível no MDS até o ano de 2008.
} 
A Tabela 4 apresenta a relação entre o total transferido pelo PBF com o custo de uma cesta básica que cumpra com os mínimos necessários para repor a energia de uma família. A representatividade média na Região Sul foi de $12,43 \%$, ou seja, o valor médio transferido pelo PBF quando despendido integralmente com alimentação, com os produtos que compõem a cesta básica do DIEESE, permite suprir 12,43\% dos custos da Cesta Básica Nacional em uma dada família. O Paraná é a Unidade Federativa com a Cesta Básica Nacional mais barata da Região Sul, entretanto é a que possui menor representatividade média na relação considerada, isto se deve, sobretudo, ao número de indivíduos que compõe a família, que também é a maior na região.

A relação apresenta que o valor mensal repassado às famílias beneficiadas é, portanto, insuficiente para suprir integralmente as necessidades familiares com alimentação, o que reforça o objetivo do programa em complementar a renda familiar, e não com única fonte renda.

Para os cinco anos considerados, a proporção do benefício do PBF em relação ao Custo da Cesta Básica familiar se elevou em 39,34\% na Região Sul, com destaque para o Paraná cuja elevação foi de 56,20\%. Esta elevação na relação é explicada pelo aumento no valor das transferências que foi mais de 55\% superior ao aumento no custo da Cesta Básica Nacional; enquanto, para o período considerado, as transferências do PBF se elevaram em 64,81\% na região, o custo da Cesta Básica Nacional se elevou em 35,7\%.

Tabela 4 - Região Sul e Unidades da Federação da Região Sul: Relação entre o total transferido pelo PBF com o custo da Cesta Básica Nacional de uma família(em \%)

\begin{tabular}{l|c|c|c|c|c|c}
\hline & $\mathbf{2 0 0 4}$ & $\mathbf{2 0 0 5}$ & $\mathbf{2 0 0 6}$ & $\mathbf{2 0 0 7}$ & $\mathbf{2 0 0 8}$ & Média (2004-2010) \\
\hline Santa Catarina & 11,05 & 11,59 & 13,51 & 13,92 & 13,95 & 12,81 \\
\hline Paraná & 9,13 & 10,79 & 13,01 & 14,26 & 13,83 & 12,20 \\
\hline Rio Grande do Sul & 9,58 & 11,24 & 13,01 & 13,28 & 14,37 & 12,30 \\
\hline Região Sul & 9,90 & 11,21 & 13,18 & 13,80 & 14,06 & 12,43 \\
\hline
\end{tabular}

Fonte: MDS, SAGI - Matriz de Informações Sociais, 2010 e Departamento Intersindical de Estatística e Estudos Socioeconômicos (DIEESE). (Elaboração Própria).

As análises referentes à transferência de renda não se limitam à esfera social da economia, os dados apresentados pelo MDS apontaram a expres- 
sividade do PBF na dinamização das economias locais das regiões mais pobres na Região Sul do Brasil.

Nesta perspectiva, o montante transferido anualmente pelo PBF mostrou não ser desprezível à economia da região. O Gráfico 6apresenta a relação percentual entre o valor anual transferido pelo PBF, entre 2004 e 2010, comparativamente às transferências municipais do Tesouro Nacional.

A média da relação na Região Sul foi de 7,01\% nos sete anos analisados, os valores oscilaram em todas as Unidades Federativas. Em Santa Catarina, os valores transferidos pelo Programa Bolsa-Família representaram média de $4,47 \%$ do valor repassado pelas transferências municipais. A relação foi mais expressiva no Rio Grande do Sul e Paraná, cuja média foi superior a 8\%.

Gráfico 6 - Unidades da Federação da Região Sul: Relação entre o total transferido pelo PBF com as demais transferências constitucionais municipais, 2004-2009, (em \%)

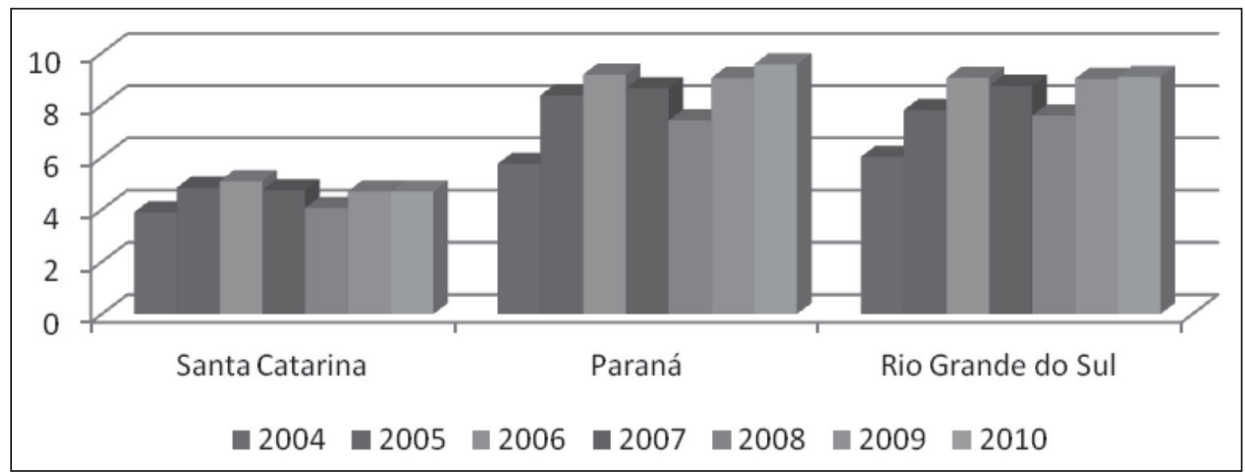

Fonte: MDS, SAGI - Matriz de Informações Sociais, 2010 e Tesouro Nacional - Sistema de Informação de Custos do Governo Federal, Estados e Municípios, transferências constitucionais. (Elaboração Própria).

Os dados apresentados no Gráfico 6 revelam que o PBF vem assumindo um peso significativo na composição da renda nas Unidades Federativas da Região Sul; tendo em vista a relevância para os municípios dos valores transferidos pelo PBF, deve se ter em mente o efeito dinamizador que ele provoca na economia. Marques (2005) associa os efeitos dos gastos privados com os governamentais na economia, levando em conta o efeito multiplicador keynesiano que eleva o valor do produto a um montante superior em 
relação aos gastos iniciais destinados ao consumo. Desta forma, os recursos do $\mathrm{PBF}$ repassados às famílias geram novas demandas que além dos efeitos sobre a renda, também eleva o número de contratações, tal processo tem continuidade em diferentes setores da economia.

Uma segunda observação apontada por Marques (2005) diz respeito às famílias beneficiadas pelo PBF, ou seja, aquelas de menor renda, uma vez que o programa focaliza as famílias pobres e extremamente pobres. Estas famílias apresentam a característica de destinarem uma maior parcela de suas rendas ao consumo quando suas rendas aumentam em uma unidade, ainda de acordo com a teoria keynesiana; ou seja, elas apresentam uma maior propensão marginal ao consumo o que, consequentemente, eleva o efeito multiplicador das transferências governamentais.

\section{CONSIDERAÇÕES FINAIS}

Este trabalho buscou apresentar as características dos Programas de Transferência de Renda Condicionados que difundiram rapidamente em países subdesenvolvidos na década de 90, cujo principal objetivo visava a redução da pobreza tanto no curto como no longo prazo através da associação da transferência de renda com a existência das condicionalidades. O desenho institucional foi explorado a fim de esclarecer os mecanismos de combate à pobreza; primeiramente apresentou as características gerais destes programas para que num momento posterior fosse explorado o caso brasileiro: O Programa Bolsa Família.

Em virtude da profunda desigualdade socioeconômica da economia brasileira, o trabalho evidenciou a heterogeneidade da incidência do PBF nas regiões brasileiras. Esta heterogeneidade significa que o PBF admitiu maiores proporções na transferência e no número de famílias atendidas nas regiões com maior incidência de pobreza, o que confirma a política de focalização do programa.

As análises focaram na Região Sul do Brasil e os resultados apontaram para a aceitação do programa e o compromisso do Governo Federal no combate à pobreza ao analisar o crescimento do número de famílias atendidas e do valor monetário transferido pelo PBF desde sua criação. Uma segunda importante constatação está no valor médio das transferências do programa, 
elas se apresentaram como consideráveis mediante a renda média da região. O valor médio do benefício, principalmente no Paraná e Rio Grande do Sul onde representam uma fatia maior na renda, ainda mostrou-se significativo para a supressão das necessidades mediatas, além de não desestimular o incentivo ao trabalho, uma vez o benefício mensal não ser suficiente para suprir a integralidade das necessidades familiares.

Os resultados ainda apontam para a elevada e ascendente cobertura do programa, ou seja, o PBF tem sido eficiente em atender o público alvo. Desta forma, o PBF tem sido eficiente na seleção das famílias mais vulneráveis da Região Sul, além de beneficiar uma parcela considerável desta camada oferecendo a elas mecanismos e oportunidades de supressão da situação socioeconômica que se encontram.

A dinamicidade econômica gerada pelo programa é outro ponto abordado pelo trabalho em dois aspectos: no primeiro analisou o montante transferido pelo PBF aos Estados da Região Sul do Brasil e constata que ele apresenta uma elevada representatividade frente às demais transferências intergovernamentais, e, além disto, ele estimula a economia ao ser repassado às famílias com elevada propensão marginal a consumir, o que gera um efeito multiplicador na economia; o segundo aspecto reforça algumas das hipóteses citadas anteriormente ao comparar os valores transferidos com o custo da cesta básica de cada Unidade Federativa, as análises mostram que os valores transferidos pelo programa, apesar de não serem suficientes, permite suprir parte das necessidades mediatas com alimentação das famílias beneficiadas.

O PBF reflete o predomínio das políticas focalizadas de caráter liberal adotadas no Brasil. Parte da literatura especializada atribui peso significativo do programa nas atuais transformações econômicas e social brasileiras. Entretanto, para que o programa atinja proporções e resultados maiores, é essencial que os mecanismos que rompem com a perpetuação da pobreza no longo prazo sejam revistos e merecedores de uma maior atenção. Apesar da existência dos programas complementares, as análises da literatura especializada mostraram-se inconclusivas e demasiadamente questionáveis sobre os resultados dos PTRC no longo prazo, não somente no caso brasileiro, mas em quase toda a América Latina. Além disto, a mera ampliação da transferência monetária tem mostrado ser incapaz de romper com as características econômicas e sociais das famílias beneficiadas configurando, 
portanto, como um mecanismo de aliviar os problemas imediatos sem, no entanto, ser capaz de erradicá-los.

Desta forma, mesmo reconhecendo os méritos do programa no combate a pobreza e a promoção do produto econômico, a ausência de políticas públicas direcionadas às necessidades básicas da população e a oferta de serviços públicos de qualidade compromete a promoção da cidadania entre as famílias beneficiadas.

Enfim, apesar de destacado mudanças importantes necessárias na sua estruturado PBF, conclui-se que os resultados apresentados aqui colocam o programa brasileiro de transferência de renda condicionado como um importante programa social, tanto na esfera econômica quanto social na Região Sul do Brasil, apesar desta região concentrar consideráveis indicadores sociais se comparado com a média nacional.

\title{
AN ANALYSIS OF THE "PROGRAMA BOLSA FAMÍLIA" IN SOUTHERN BRAZIL
}

\begin{abstract}
Abtract
In 2004, the Family Grant Program was created, involving the old programs of income transference that were present in Braziland aiming to establish a better organization, besides attending different families in poverty conditions, according to their different needs. This study has, as its main goal, promoting an analysis on the results related to the Family Grant Program in the Southern part of Brazil, considering the country's regional specificities. As a methodological procedure, besides a brief reading revision on the economic literature, a statistical study and a qualitative analysis of data from the Family Grant Program were carried out. The conclusion is that in the Southern part of the country, the Program has had effect on poverty relieving and on the economic product increase.
\end{abstract}

Keywords: Family Grant Program, Southern Brazil and Transfer of Income.

JEL Classification: O2, R2, I3. 
Henrique Rogê Batista

\section{REFERÊNCIAS}

COHN, Amélia. Políticas Sociais e Pobreza no Brasil. Disponível em: $<$ www.ipea.gov.br/ppp/index.php/PPP/article/view/138>. Acessado em: 16/08/2011.

COTTA; Tereza Cristina Silva. Visões de Proteção Social e Transferência de Renda Condicionada no Brasil e no México. Tese de Doutorado. Universidade de Brasília. Brasília (2009).

COTTA, Tereza Cristina \& PAIVA, Luis Henrique. O Programa Bolsa Família e a Proteção Social no Brasil. p.57-101. In: Bolsa Família 2003 - 2010: Avanços e Desafios. Vol1. Brasília 2010.

Departamento Intersindical de Estatística e Estudos Sócio-Econômicos. Bancos de dados da Cesta Básica Nacional. Disponível em: <http:// turandot.dieese.org.br/bdcesta/capital.html>. Acessado em: 20/10/2011.

DRAIBE. Sonia. Programas de Transferências Condicionadas. América Latina - Desafios da Democracia e do Desenvolvimento. Políticas Sociais para além da crise. Editora Campus. p. 103-143. Rio de Janeiro (2009).

FONSECA, Ana Maria Medeiros \& VIANA, Ana Luíza d'Ávila. Direito à saúde, atenção básica e transferências condicionadas de renda na América Latina. Disponível em: <http://www.scielo.br/scielo.php?pi$\mathrm{d}=\mathrm{S} 1413-81232007000600012 \&$ script $=$ sci_arttext\&tlng=e\#quad01 $>$. Acessado em 20/01/2011.

HOFFMANN, Rodolfo. Transferências de Renda e Redução da Desigualde no Brasil e em Cinco Regiões, entre 1997 e 2005. In Desigualdade de Renda no Brasil: uma análise da queda recente. Volume 2. Editora IPEA. Brasília (2007).

$I B G E$ - Instituio Brasileiro de geografia e Estatística (2011). Acesso em Janeiro-Maio de 2011, disponível em IBGE: http://www.ibge.gov.br 
IPEA - Instituto de Pesquisa Econômica Aplicada (2011). Acesso em Janeiro-Junho de 2011, disponível em IPEAdata: http://www.ipeadata.gov. br/Default.aspx

MARQUES, Rosa Maria. A importância do Bolsa Família nos municípios brasileiros. Diretoria do Departamento de Avaliação e Monitoramento; Secretaria de Avaliação e Gestão da Informação. n 1 , MDS-SAGI. Brasília (2005). Disponível em: <http://www.redesabara.org.br/downloads/2009/ Programas\%20sociais_bolsa\%20famlia_completo\%5B1\%5D.pdf $>$. Acessado em: 21/06/2011.

MEDEIROS. Carlos Aguiar. Desenvolvimento Econômico e Estratégias de Redução da Pobreza e das Desigualdades no Brasil. Ensaios FEE, v. 24, n. 2, p. 323-350. Porto Alegre (2003).

MICHEL, Renaut. "Distribuição de renda e pobreza no Brasil: uma proposta de agenda”. In: SICSÚ, João; OREIRO, José Luís; PAULA, Luiz Fernando de (orgs). Agenda Brasil:

políticas econômicas para o crescimento com estabilidade de preços. Barueri: Manok, 2003.

Ministério do Desenvolvimento Social e Combate à Fome. Matriz de Informação Social. Disponível em: http://aplicacoes.mds.gov.br/sagi/mi2007/ tabelas/mi_social.php. Acessado em: 20/11/2011.

PEQUENO, Rosangela dos Santos Alves. O Programa Bolsa-Família: seus efeitos econômicos e sociais na região Nordeste do Brasil. I Mostra Nacional e I Prêmio Nacional de Estudos sobre o Bolsa-Família, Trabalho Completo (2008).

PINHEIRO. Vinícius C.. Modelos de Desenvolvimento e Políticas Sociais na América Latina em uma Perspectiva Histórica. Disponível em: $<$ http:// www.ipea.gov.br/ppp/index.php/PPP/article/view/141/143>. Acessado em: 10/09/2011. 
ROCHA. Sônia. Impacto sobre a Pobreza dos Novos Programas Federais de Transferência de Renda. Revista Economia Contemporânea. p. 153-185. Rio de Janeiro (2005).

SANTANA, JomarÁlace. A Evolução dos Programas de Transferência de Renda e o Programa Bolsa Família. Trabalho apresentado no Seminário População, Pobreza e Desigualdade. Belo Horizonte (2007).

SOARES, Fábio Vera; RIBAS, Rafael Perez \& OSORIO, Rafael Guerreiro. Avaliando o Impacto do Programa Bolsa Família: Uma comparação com programas de transferência condicionada de renda de outros países. Disponível em: <http://www.ipc-undp.org/pub/port/IPCEvaluationNote1. pdf>. Acessado em: 07/01/2011.

SOARES, Sergei etalli. Programas de Transferência Condicionada de Renda no Brasil, Chile e México: Impactos sobre a desigualdade. Disponível em: < www.ipea.gov.br/sites/000/2/publicacoes/tds/td_1293.pdf > Acessado em: 28/09/2011.

Tesouro Nacional. Estados e Municípios - Transferências Constitucionais. Disponível em: $<$ http://www.tesouro.fazenda.gov.br/estados_municipios/transferencias_constitucionai s.asp >. Acessado em 20/10/2011. 